\title{
Developmental Changes in Eye-Blink Conditioning and Neuronal Activity in the Inferior Olive
}

\author{
Daniel A. Nicholson and John H. Freeman Jr \\ Department of Psychology, University of lowa, lowa City, lowa 52242
}

Neuronal activity was recorded in the dorsal accessory inferior olive in infant rats during classical conditioning of the eye-blink response. The percentage and amplitude of eye-blink conditioned responses (CRs) increased as a function of age. The magnitude of the neuronal response to the unconditioned stimulus (US) decreased with age. There were also age-specific modifications of US-elicited inferior olive neuronal activity during paired trials in which a conditioned eye-blink response was performed. The results indicate that the development of the conditioned eye-blink response may depend on dynamic interactions between multiple developmental processes within the eye-blink circuitry. Differences in the functional maturity of olivocerebellar pathways may limit the induction of plasticity in the cerebellum and thereby limit the development of eye-blink conditioned responses.

Key words: ontogeny; brainstem; olive; learning; conditioning; eyeblink
Much is known regarding the developmental changes in the neurophysiological mechanisms of learning in Aplysia californica (Carew, 1989; Marcus and Carew, 1998), but there have been few neurophysiological studies of learning in developing mammals (Freeman and Nicholson, 2000). Most of what is known about the time course of mammalian developmental changes in learning and neural function comes from correlations between the ontogeny of particular learned responses and the progression of anatomical maturation of the neural systems underlying these learned responses in adults (Green and Stanton, 1989; Diamond, 1990; Freeman and Stanton, 1991; Rudy, 1992; Stanton et al., 1992; Hunt and Campbell, 1997; Stanton, 2000). Elucidation of the specific developmental mechanisms of learning will require the use of various neurophysiological techniques and consideration of the dynamic interactions between multiple developmental processes within a well characterized neural circuit (Freeman and Nicholson, 2000; Stanton, 2000).

Studying the classically conditioned eye-blink response in infant rats provides a unique opportunity to examine the relationship between the neural maturation of an extensively characterized neural circuit (Lavond et al., 1993; Thompson and Krupa, 1994; Steinmetz, 1998) and the ontogeny of associative learning (Stanton et al., 1992; Stanton and Freeman, 1999; Stanton, 2000). The parameters that influence the rate and strength of eye-blink conditioning have also been characterized extensively, which facilitates both the design of experiments and the interpretation of results (Gormezano et al., 1962, 1983; Gormezano, 1966).

The cerebellum, the pontine nuclei, and the inferior olive are essential components of the neural circuitry underlying the eyeblink conditioned response (CR) in adult organisms (Lavond et al., 1993; Thompson and Krupa, 1994; Steinmetz, 1998). Electrophysiological analyses found that the inferior olive responds most reliably to stimuli that are commonly used as unconditioned stimuli in eye-blink conditioning, such as air puffs, taps, and shocks (Armstrong et al., 1968; Armstrong, 1974; Gellman et al., 1983; Sears and Steinmetz, 1991; Weiss et al., 1993). Lesions of the dorsal

\footnotetext{
Received June 30, 2000; revised Aug. 18, 2000; accepted Aug. 22, 2000.

This work was supported by NS38890-01A1. We thank Dr. Mark E. Stanton for the eye-blink conditioning equipment; Dr. Jeremy Payne for the neuronal spike separation and analysis software; and Adam Muckler and Brian Nolan for help with data collection.

Correspondence should be addressed to John H. Freeman Jr, Department of Psychology, University of Iowa, Seashore Hall, Iowa City, Iowa, 52242. E-mail: john-freeman@uiowa.edu.

Copyright (C) 2000 Society for Neuroscience $0270-6474 / 00 / 208218-09 \$ 15.00 / 0$
}

accessory inferior olive impair retention and acquisition of the eye-blink CR (McCormick et al., 1985; Yeo et al., 1986; Mintz et al., 1994). Furthermore, it has been demonstrated using lesions, electrical stimulation, and pharmacology that the climbing fibers from the inferior olive to the cerebellum provide the necessary and sufficient US information to support learning of the eye-blink CR (McCormick et al., 1985; Mauk et al., 1986; Steinmetz et al., 1989; Harvey and Romano, 1993; Du and Harvey, 1997). The olivocerebellar system has also been implicated as a critical component in adaptation of the vestibulo-ocular reflex (Ito, 1984; Raymond et al., 1996) and load compensation (Gilbert and Thach, 1977; Thach et al., 1992).

Developmental changes within the olivo-cerebellar circuit (Crepel, 1971, 1972, 1974; Altman, 1972; Berry and Bradley, 1976, 1982; Gardette et al., 1985) could play a pivotal role in the ontogeny of eye-blink conditioning. Freeman and Nicholson (2000) found an age-related increase in neuronal activity in the cerebellar interpositus nucleus after the onset of the conditioned and unconditioned stimuli during eye-blink conditioning in infant rats. It was proposed that the weaker response in the interpositus neurons to the US in younger rats might affect the rate and strength of eye-blink conditioning by limiting the induction of cerebellar neuronal plasticity.

This report describes the results of an examination of stimulusevoked and learning-related modifications of neuronal activity in the dorsal accessory inferior olive (the US pathway) of infant rats during eye-blink conditioning and US-alone trials.

\section{MATERIALS AND METHODS}

Subjects. The subjects were 12 Long-Evans rat pups trained on either postnatal day (PND) 17-18 $(n=6)$ or PND24-25 $(n=6)$. The electrode assembly of one PND17-18 rat pup was damaged between the pretraining session and the first session of paired training, and one PND17-18 did not receive US-alone trials during the first session of paired training. The rats were housed in the animal colony in Spence Laboratories at the University of Iowa. The rats were maintained on a $12 \mathrm{hr}$ light/dark photoperiod, with light onset at 6:30 A.M.

Surgery. The rat pups were given intraperitoneal injections of ketamine $(60 \mathrm{mg} / \mathrm{kg})$ and xylazine $(7.5 \mathrm{mg} / \mathrm{kg})$ for anesthesia. The rat's head was positioned in an infant stereotaxic head holder and aligned in three planes, to bring it into the orientation required for placement of the electrodes. The rats were fitted with differential EMG electrodes that were implanted in the left eyelid muscle (orbicularis oculi) and a ground electrode was attached to a stainless steel skull hook. The EMG electrode leads terminated in gold pins in a plastic connector, which was secured to the skull with dental acrylic. A bipolar stimulating electrode (for delivering the shock US) was implanted subdermally, immediately caudal to the left eye. The bipolar electrode terminated in a plastic connector that was secured to the skull by dental acrylic.

A bundle of eight insulated stainless steel electrodes $(25 \mu \mathrm{m})$ was 
implanted in the right dorsal accessory inferior olive (DAO) of each rat under electrophysiological and stereotaxic guidance. The stereotaxic coordinates for the DAO were taken from lambda (PND16: anteriorposterior $(\mathrm{AP})=-2.1 \mathrm{~mm}$, medial-lateral $(\mathrm{ML})=0-0.5 \mathrm{~mm}$, and dorsal-ventral $(\mathrm{DV})=-8.8 \mathrm{~mm}$; PND23: $\mathrm{AP}=-2.4 \mathrm{~mm}, \mathrm{ML}=-0.4$ $\mathrm{mm}, \mathrm{DV}=-9.3)$. While the electrode was lowered to the inferior olive, the cerebellar cortex and cerebellar deep nuclei could be identified by their characteristic neuronal firing patterns. The inferior olive was $\sim 4-4.5 \mathrm{~mm}$ ventral to the cerebellar deep nuclei and was identified by its characteristic low-frequency discharge of single action potentials occasionally followed by bursts of two to five smaller "wavelets" with a total duration ranging from 3 to $\sim 10 \mathrm{msec}$ (Armstrong and Harvey, 1968; Armstrong et al., 1968; Crill, 1970; Llinas et al., 1974; Headley and Lodge, 1976; Gellman et al., 1983; Sears and Steinmetz, 1991; Weiss et al., 1993). The electrodes were held in place by a microelectrode connector and dental acrylic applied to the skull. The surgical site was closed with sutures on both sides of the electrode plug. The connectors for the EMG electrodes, bipolar stimulating electrode, and microwire electrodes were connected to lightweight cables that allowed the rats to move freely during conditioning.

Identification of inferior olive neurons. While the electrode was lowered to the inferior olive, the neuronal activity was monitored to recognize its characteristic firing pattern (Armstrong et al., 1968; Armstrong and Harvey, 1968; Crill, 1970; Llinas et al., 1974; Headley and Lodge, 1976; Gellman et al., 1983; Sears and Steinmetz, 1991; Weiss et al., 1993), which has been likened to "popcorn popping" (Gellman et al., 1983). Waveforms could be isolated and overlaid on the digital oscilloscope to display the consistent shape of the olivary neuronal potential, occasionally followed by variable wavelets. Rarely (one PND17-18 rat and two PND24-25), lemniscal fiber potentials were encountered and were easily distinguished from inferior olive neurons by their very short duration action potentials, which were never followed by small wavelets and often were of greater amplitude than inferior olive neurons (Crill, 1970). Moreover, the lemniscal fiber potentials were usually only transiently present during surgery. In contrast, the activity of identified DAO neurons was generally present throughout training.

Conditioning apparatus. The conditioning apparatus consisted of an electrically shielded small-animal sound attenuation chamber (BRS/LVE Laurel, MD). Within the sound attenuation chamber was a small-animal operant chamber (BRS/LVE) where the rats were kept during conditioning. One wall of the operant chamber was fitted with two speakers that independently produced tones of up to $130 \mathrm{db}$ sound pressure level (SPL), with a frequency range of $\sim 1000-9000 \mathrm{~Hz}$. The back wall of the sound attenuating chamber was equipped with a small light. The electrode leads from the rat's headstage were connected to peripheral equipment and a Pentium computer. Computer software controlled the delivery of stimuli and the recording of eyelid EMG activity. EMG activity was recorded differentially, filtered, amplified, and integrated by equipment that was described in previous studies (Stanton et al., 1992; Freeman et al., 1995a,b; Freeman and Nicholson, 2000).

Conditioning procedure. The rat pups received training sessions that consisted of 100 trials each. Three sessions were run for each day of training, at $\sim 4 \mathrm{hr}$ intervals. During the first training session, the rats were given unpaired presentations of a tone conditioned stimulus (CS) $(2.0 \mathrm{kHz}$, $300 \mathrm{msec}, 85 \mathrm{~dB}$ SPL) and a periorbital shock US (6 msec, $4 \mathrm{~mA}$ ). The rats were then given five training sessions, which consisted of 90 paired presentations of the tone conditioned stimulus and the shock unconditioned stimulus, followed by 10 US-alone trials. In the paired condition, training sessions consisted of nine blocks of 10 trials of delay conditioning. Of these, nine trials involved pairings of the auditory CS and a $6 \mathrm{msec}$ periorbital-shock US, and one trial involved the pairing of the auditory CS and a $1 \mathrm{msec}$ periorbital-shock US. The CS coterminated with the 1 and 6 msec US, yielding interstimulus intervals of 299 and 294 msec, respectively. Interspersed among the 10 US-alone trials were five trials each involving the $1 \mathrm{msec}$ US and the $6 \mathrm{msec}$ US. Implementing the $1 \mathrm{msec}$ US paired trials provided the opportunity to assess the US-elicited activity of the DAO neurons at their shortest possible latency ( $\sim 8-9 \mathrm{msec}$ ) (Armstrong et al., 1968; Armstrong, 1974; Crill, 1970; Cook and Wiesendanger, 1976). Trials were separated by a variable intertrial interval that averaged $30 \mathrm{sec}$ (range $=18-42 \mathrm{sec}$ ). CRs were defined as responses that crossed a threshold of 0.4 units (amplified and integrated arbitrary units) above baseline during the CS period after $80 \mathrm{msec}$. Behavioral data were examined from computer records of EMG responses. Previous studies have shown that the paired training protocol used in this study established associative eye-blink CRs (Stanton et al., 1992; Freeman et al., 1993).

Stimulation procedure. A subset of rats at each age $(n=2$ per group) was given electrical stimulation through the recording electrodes. The stimulating current was a single $50 \mu \mathrm{sec}$ pulse starting at $5 \mu \mathrm{A}$ and steadily incremented in $10 \mu \mathrm{A}$ current steps until EMG responses or movements could be detected, or until $1500 \mu \mathrm{A}$. Eyelid EMG responses were amplified, filtered, and recorded for off-line analysis. Movements of other body parts were observed visually.

Neuronal recording procedure. The activity of each microwire electrode was initially passed through a unity gain JFET preamplifier (NB Labs, Denison, TX). The outputs of the JFET preamplifier were fed into an eight-channel programmable amplifier (Lynx-8), filtered between 300 and $6000 \mathrm{~Hz}$, and amplified at a gain of 10,000. The outputs of the amplifiers were fed into a computer-controlled acquisition system at $20 \mathrm{kHz}$ per

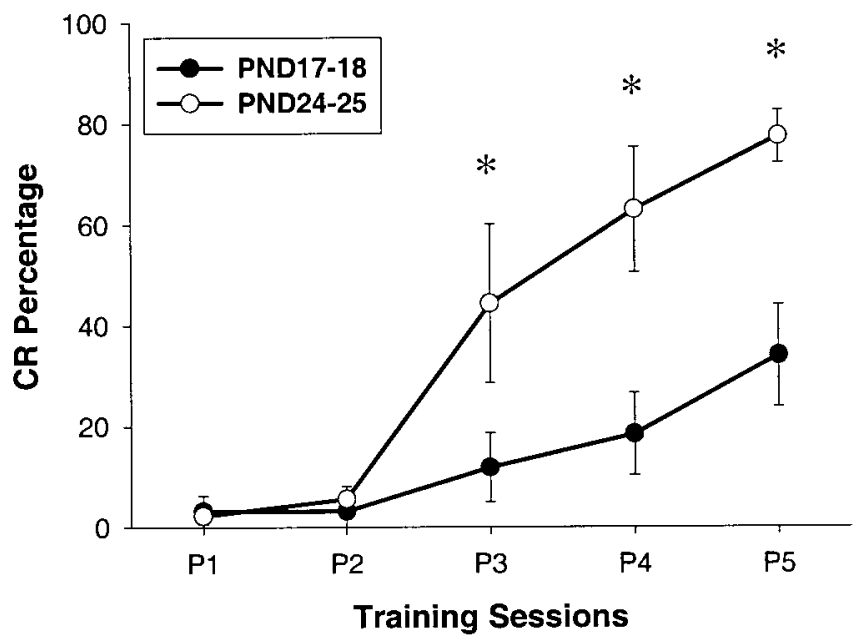

Figure 1. Mean ( \pm SEM) percentage of conditioned responses from infant rats trained on PND17-18 (O) and PND24-25 (O) across the five sessions of paired training (*significant group differences).

channel (Datawave Technologies, Workbench-32), where thresholding was used to detect and extract waveforms of units with signal-to-noise ratios of at least $3: 1$. The waveforms were saved as separate 32 point data chunks. Two voltage thresholds were used. Waveforms that crossed the lower threshold but did not cross the upper threshold within the 32 sample points were recorded to computer disk. The multiple unit records were then separated using custom software. This software displays all of the waveforms that were recorded during a particular data collection period (usually a training session). The user may examine any individual spike waveform that was recorded during the training session. A template-matching program was used to identify all of the spikes with similar waveform characteristics. This technique effectively isolated single units from multiunit records (Freeman and Nicholson, 1999, 2000).

Data analysis. The behavioral data were examined for each training session. Repeated measures ANOVAs were performed for the CR percentage, CR amplitude, CR latency, unconditioned response (UR) percentage, and UR amplitude.

Peristimulus-time histograms of the firing rates of each unit were created for the entire period of the conditioning trials $(1 \mathrm{sec})$ for the pretraining, first, and fifth training sessions. It was expected that most units in the DAO would fire action potentials in response to the US (Armstrong et al., 1968; Crill, 1970; Armstrong, 1974; Cook and Wiesendanger, 1976; Gellman et al., 1983, 1985; Sears and Steinmetz, 1991; Weiss et al., 1993). The neuronal activity during the US period was analyzed using Wilcoxon signed rank tests (Kubota et al., 1996; Freeman and Nicholson, 1999, 2000). The onset latency and peak latency of each single unit was determined from individual unit histograms and subjected to two-tailed $t$ tests $(p<$ $0.05)$ comparing between-group within-session differences and withingroup between-session differences. Separate analyses were conducted for the peak and onset latencies for the $6 \mathrm{msec}$ and $1 \mathrm{msec}$ paired trials and the $6 \mathrm{msec}$ and $1 \mathrm{msec}$ US-alone trials for the unpaired pretraining session, and the first and fifth paired training sessions. The post-US period (i.e., immediately after the offset of the US) was divided into $10 \mathrm{msec}$ intervals (10 for the US). The period during the presentation of the US was not analyzed because of the stimulation artifact.

Histology. On the day after training, the rats were killed with a lethal injection of sodium pentobarbital $(90 \mathrm{mg} / \mathrm{kg})$ and transcardially perfused with $100 \mathrm{ml}$ of physiological saline followed by $300 \mathrm{ml}$ of $3 \%$ formalin. After perfusion, the brains were post-fixed in the same fixative for a minimum of $24 \mathrm{hr}$ and subsequently sectioned at $50 \mu \mathrm{m}$ with a sliding microtome. Sections were then stained with cresyl violet. The locations of the recording electrodes were confirmed by examining serial sections.

\section{RESULTS}

\section{Behavior}

The rats trained on PND24-25 exhibited significantly greater CR percentage and amplitude during sessions 3-5 than the rats that were trained on PND17-18 (Fig. 1). The average onset latency of the CR was lower in the rats trained on PND24-25 than in the rats trained on PND17-18 during sessions 3-5. These data replicate the behavioral results of previous studies and indicate that the eyeblink conditioned response develops substantially between PND17 and PND24 (Stanton et al., 1992; Freeman et al., 1993, 1995a,b; Freeman and Nicholson, 2000). There were no differences in the amplitude or percentage of the unconditioned response between 


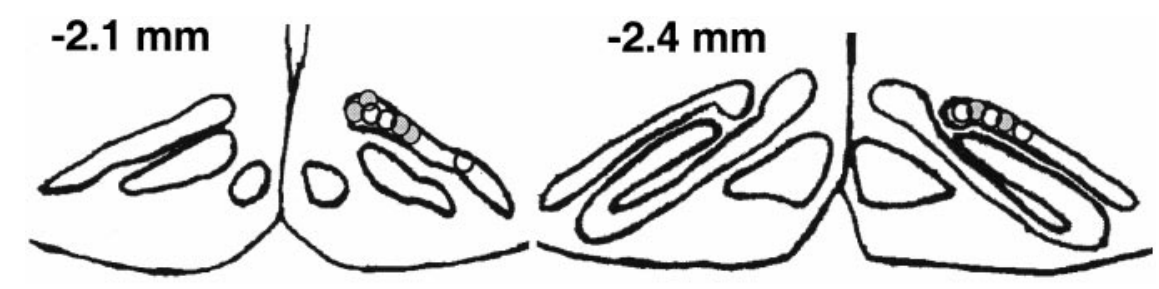

Figure 2. Drawing of coronal sections of the rat brain with labels indicating the placement of the tips of the electrode bundles in the right DAO of infant rats trained on PND17-18 (white circles) or PND24-25 (gray circles). Numbers in each drawing indicate the approximate distance from lambda (in millimeters).

the two age groups throughout training. This result indicates that the developmental change in conditioned response acquisition was not caused by a developmental change in performance of the eye-blink response (Stanton et al., 1992; Freeman et al., 1993, 1995a,b; Freeman and Nicholson, 2000).

The behavioral data were evaluated statistically by ANOVA. Analyses of both CR percentage and amplitude yielded significant interactions involving the group and training session factors (CR percentage: $F_{(4,36)}=8.226, p<0.02$; CR amplitude: $F_{(4,36)}=3.12$, $p<0.037$ ). Post hoc tests (Tukey's HSD) revealed a significantly greater percentage and amplitude of CRs for the rats trained on PND24-25 relative to the rats trained on PND17-18 during sessions 3-5 (all comparisons, $p<0.05$ ). The onset latency of the CR was examined for trials from sessions $3-5$ because most of the rats failed to produce CRs during test trials before session 3. The ANOVA revealed a significant effect of the group factor $\left(F_{(1,9)}=\right.$ 6.793, $p<0.03$ ), which was attributable to lower CR latencies in the rats trained on PND24-25 (means: PND17-18 = $235.9 \mathrm{msec}$; PND24-25 = $155.8 \mathrm{msec}$ ).

\section{Electrode placement}

All of the units used in the data analysis of this experiment were recorded from the rostromedial portion of the right DAO. Of the 12 electrode bundles, 11 were placed in the rostromedial portion of the DAO, and one was placed in the rostrolateral portion (Fig. 2).

\section{Inferior olive neuronal activity}

During the course of training, three electrode wires in one PND17-18 rat pup and two electrode wires in one PND24-25 rat pup exhibited lemniscal fiber potentials, which were easily identified by their waveform characteristics (see Materials and Methods) (Crill, 1970). Further investigation during off-line analysis confirmed that these potentials were quite unlike any of the rest of the neuronal waveforms, having shorter duration depolarizations, very small and brief, if any, valleys after the action potential peak voltage, and higher peak voltage values (amplitude). It was concluded that these potentials were from medial lemniscal axons, or at least not inferior olive neurons, by their distinct firing characteristics, their presence on only a few trials in each of the two rats, and their clear differences in waveforms from all other inferior olive neurons, and therefore they were not included in any of the analyses. The numbers of units at PND17-18 were 182, 133, and 163 for pretraining, paired session 1 , and paired session 5, respectively. The numbers of units at PND24-25 were 195, 181, and 205 for pretraining, paired session 1, and paired session 5, respectively.

Figure 3 shows the activity of representative single units that were recorded during the US-alone trials in the pretraining session on PND17 (top) and PND24 (bottom). Note that almost all activity occurs after US onset, with most of the activity timelocked to within $100 \mathrm{msec}$ after US onset. Also, the response in the PND17 neuron was more consistently timed, more robust, and peaked sooner after the US than in the PND24 neuron. Notice that the PND17 neuron in Figure 3 displays a bimodal distribution, sometimes firing at a similar latency to the PND24 neuron, and other times firing $\sim 10-20 \mathrm{msec}$ earlier. As can be seen in Figure $4 A$, the peak latency of olivary neurons in PND17 rat pups is significantly shorter than neurons in PND24 rat pups $(t=7.545, p<0.001)$ (Table 1). There was no age difference in onset latency. The age-related differences in US-elicited activity are seen most clearly in the mean activity of all the units (Fig. $4 B$ ), where the peak bin count is higher and occurs earlier in PND17 neurons. The
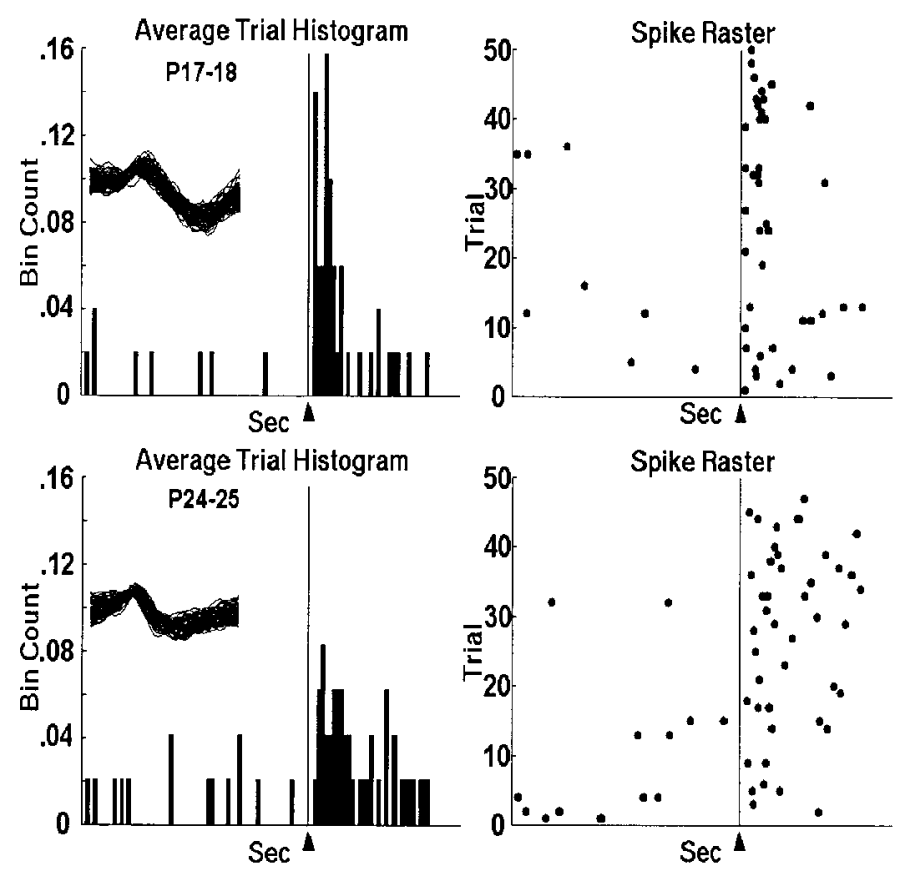

Figure 3. Histograms and raster plots of representative units recorded in the DAO during US-alone trials in pretraining from PND17 (top) and PND24 (bottom) infant rats. The arrowhead and vertical line at $0.6 \mathrm{sec}$ indicate the point in the trial when US offset occurred. The spike overlays are $1.6 \mathrm{msec}$ (each waveform is 32 data points at $20 \mathrm{kHz}$ ).

PND17-18 group data also exhibit a bimodal distribution similar to the unit in Figure 3.

The neuronal activity during US-alone trials in the first paired session continued the trend established in the pretraining session (Table 1). However, the only statistically reliable difference between the two age groups on US-alone trials was the earlier peak latency in PND17 neurons after the $1 \mathrm{msec}$ US $(t=2.345, p<$ 0.02 ). Figure 5 shows representative single units that were recorded during the paired trials in session 1 . Note that the neurons at both ages appeared to have more consistently timed responses to the US compared with the pretraining session, but the PND17 neuron (top panel) peaked earlier and more robustly. There was an age-related increase in onset $(t=4.451, p<0.001)$ and peak $(t=9.731, p<$ $0.001)$ latencies for the $6 \mathrm{msec}$ paired trials, and the onset $(t=$ 4.053, $p<0.001)$ and peak $(t=4.429, p<0.001)$ latencies for the 1 msec paired trials (Table 1 ). Figure 6 shows the mean neuronal activity of all units in both ages, which exhibits the same pattern as the single units in Figure 5. The activity elicited by the CS onset is likely related to movement during the unconditioned startle response to the tone (Mortimer, 1973; Barmack and Hess, 1980; Stanton et al., 1992). Comparison of the tone-evoked startlerelated single-unit data in this experiment and the tone-evoked startle-related Purkinje cell complex spikes in monkeys (Mortimer, 1973) reveals an impressive correspondence between the monkey and the rat. There is no clear explanation for why the neuronal response is greater in the PND17 rat pups, because rats at both ages exhibit the same percentage of startle responses to the tone (Stanton et al., 1992). However, there is a clear developmental 


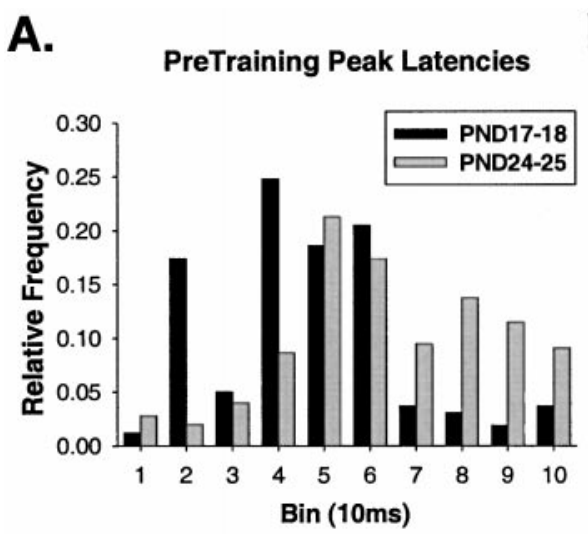

B.

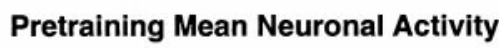

Figure 4. A, The distribution of peak latencies of responses to the US in DAO neurons from PND17 (black bars) and PND24 (gray bars) rat pups during US-alone trials in pretraining. $B$, Mean neuronal activity during the entire trial length $(1 \mathrm{sec})$ for all of the single units recorded from the DAO on PND17 (black line) and PND24 (gray line) during pretraining US-alone trials. Arrowheads indicate the offset of the US.

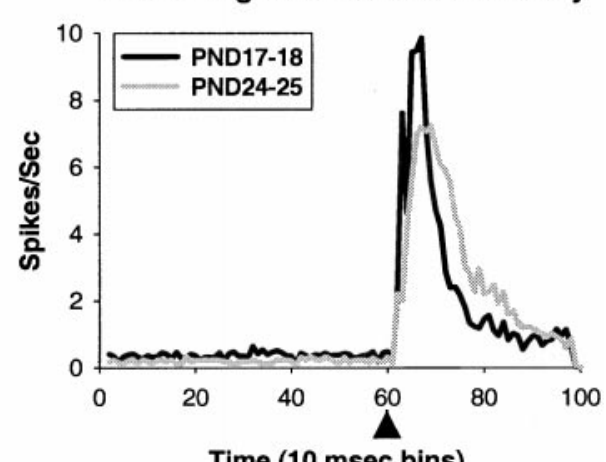

\begin{tabular}{|c|c|c|c|c|}
\hline Session & Condition & PND17-18 & PND24-25 & $p$ \\
\hline \multirow[t]{3}{*}{ Unpaired } & $6 \mathrm{msec}$ US & & & \\
\hline & Onset & $1.646(0.88)$ & $1.651(0.935)$ & 0.958 \\
\hline & Peak $^{a}$ & $4.714(2.00)$ & $6.341(2.22)$ & $<0.001$ \\
\hline \multirow[t]{12}{*}{ Session 1} & 6 msec Pair & & & \\
\hline & Onset $^{a}$ & $1.153(0.36)$ & $1.387(0.70) 1$ & $<0.001$ \\
\hline & Peak $^{a}$ & $4.166(1.46)$ & $5.83(1.99)$ & $<0.001$ \\
\hline & $1 \mathrm{msec}$ Pair & & & \\
\hline & Onset $^{a}$ & $2.901(1.70)$ & $3.707(2.14)$ & $<0.001$ \\
\hline & Peak $^{a}$ & 3.504 (1.99) & $4.502(2.33)$ & $<0.001$ \\
\hline & $6 \mathrm{msec}$ US & & & \\
\hline & Onset & $3.505(2.05)$ & $3.492(2.35)$ & 0.961 \\
\hline & Peak & $3.67(2.22)$ & $4.077(2.49)$ & 0.189 \\
\hline & $1 \mathrm{msec}$ US & & & \\
\hline & Onset & 3.308 (1.74) & $3.751(2.10)$ & 0.082 \\
\hline & Peak $^{a}$ & $3.451(1.82)$ & $4.074(2.20)$ & 0.02 \\
\hline \multirow[t]{12}{*}{ Session 5} & 6 msec Pair & & & \\
\hline & Onset ${ }^{a, b, c}$ & $1.359(0.64)$ & $1.99(1.00)$ & $<0.001$ \\
\hline & Peak $^{a, c}$ & 4.354 (1.91) & $6.97(2.32)$ & $<0.001$ \\
\hline & $1 \mathrm{msec}$ Pair & & & \\
\hline & Onset $^{a, c}$ & $3.272(2.13)$ & $4.344(2.35)$ & $<0.001$ \\
\hline & $\operatorname{Peak}^{a, c}$ & $3.963(2.51)$ & $5.262(2.36)$ & $<0.001$ \\
\hline & $6 \mathrm{msec}$ US & & & \\
\hline & Onset $^{a, c}$ & $3.305(1.74)$ & $4.24(2.60)$ & $<0.001$ \\
\hline & $\operatorname{Peak}^{a}$ & 3.609 (1.87) & $4.382(2.62)$ & 0.001 \\
\hline & $1 \mathrm{msec}$ US & & & \\
\hline & Onset $^{a}$ & $3.325(2.31)$ & 3.995 (2.37) & 0.017 \\
\hline & Peak & $3.719(2.50)$ & 4.124 (2.44) & 0.168 \\
\hline
\end{tabular}

${ }^{{ }^{a} \text { Significant age difference. }}$

${ }^{b}$ Significant difference between sessions 1 and 5 for PND17-18.

${ }^{c}$ Significant difference between sessions 1 and 5 for PND24-25.

${ }^{b, c} p<0.01$. SDs are in parentheses.

decrease in tone-evoked startle-related DAO activity (Figs. 6, 8A), which is consistent with the hypothesized source of the developmental difference in US-elicited DAO activity (see Discussion). Moreover, the lack of tone-evoked DAO activity in the rabbit (Sears and Steinmetz, 1991) may be related to the absence of the startle response in the rabbit (Gormezano, 1966). A significantly greater percentage of neurons was excited during the first $100 \mathrm{msec}$ of the US period in the rats trained on PND24 relative to the rats trained on PND17 during the 1 msec US-alone $\left(\chi^{2}=8.41, p<\right.$ $0.01,314$ units $)$ and the 6 msec US-alone trials $\left(\chi^{2}=4.66, p<\right.$ $0.05)$. There were no differences in the percentages of neurons excited during the paired trials.

During the fifth session of training, there were significant age-

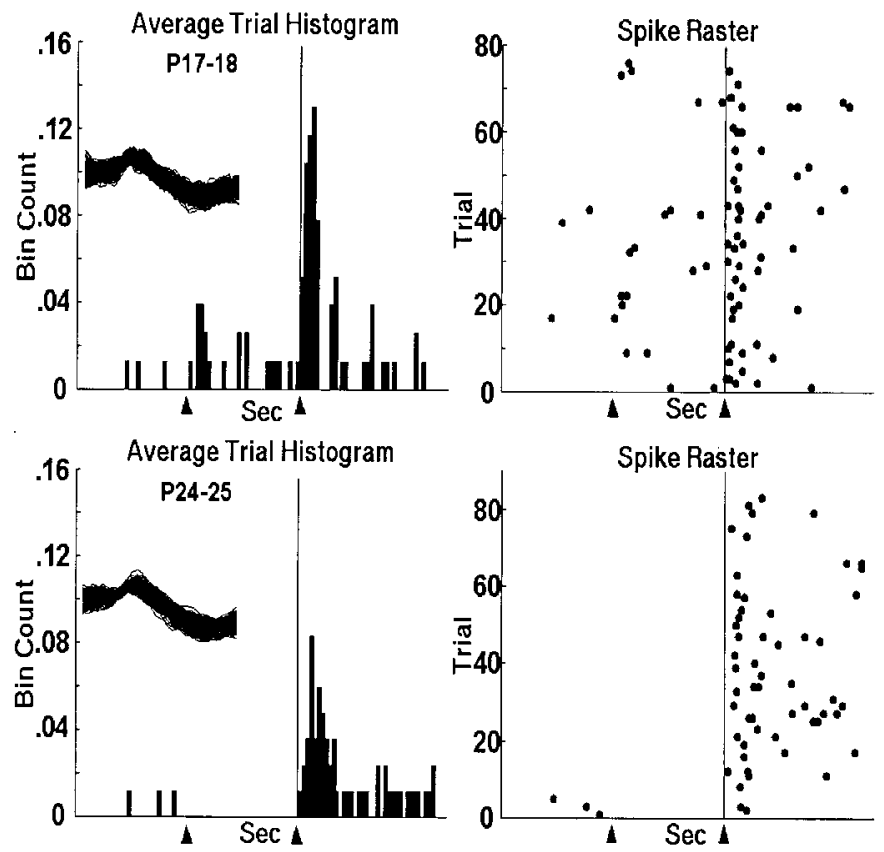

Figure 5. Histograms and raster plots of representative units recorded in the DAO during session 1 of paired training from infant rats trained on PND17 (top) and PND24 (bottom). The arrowheads and vertical line at 0.6 sec indicate the points in the trial when CS onset and US offset occurred. The spike overlays are $1.6 \mathrm{msec}$.

related increases in the onset $(t=6.574, p<0.001)$ and peak $(t=$ 9.927, $p<0.001)$ latencies in the $6 \mathrm{msec}$ paired trials; onset $(t=$ 4.79, $p<0.001)$ and peak $(t=5.453, p<0.001)$ latencies in the 1 msec paired trials; onset $(t=3.702, p<0.001)$ and peak $(t=3.201$, $p=0.001)$ latencies in the $6 \mathrm{msec}$ US-alone trials; and onset $(t=$ $2.401, p<0.02$ ) latencies for the $1 \mathrm{msec}$ US-alone trials (Table 1 ). Figure 7 shows representative single units for PND18 (top two panels) and PND25 rat pups (bottom two panels). The top of each panel is taken from trials on which the animal did not perform an eye-blink CR; the bottom of each panel is taken from trials on which the animal performed an eye-blink CR. Note that the timelocked relationship to the US is maintained in the PND18 neuron during CR trials but appears to be desynchronized or delayed in the PND25 neuron. Figure $8 B$ shows that the distribution of peak latencies in PND25 neurons appears to be skewed toward longer latencies after US offset, with a flatter shape than the distribution for the PND18 neurons.

Greater percentages of PND18 neurons were excited by the US during the $1 \mathrm{msec}$ paired trials $\left(\chi^{2}=6.117, p<0.02,368\right.$ units $)$ and the 6 msec US-alone trials $\left(\chi^{2}=5.756, p<0.02\right)$ compared with PND25 neurons. Figure $8 A$ shows the mean neuronal activity from all units in both ages. Note the more concentrated and shorter peak latency during the non-CR trials in PND25 neurons, and the lack 


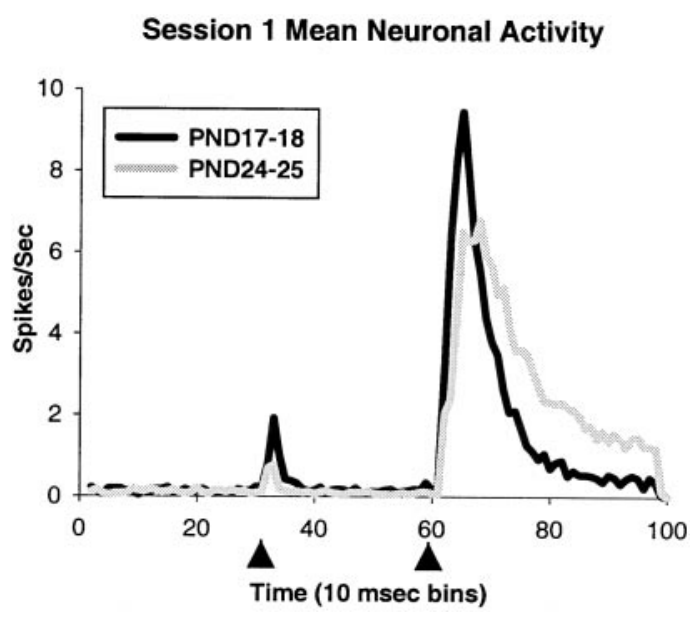

Figure 6. Mean neuronal activity during the entire trial length $(1 \mathrm{sec})$ for all of the single units recorded from the DAO from PND17 (black line) and PND24 ( gray line) rat pups during $6 \mathrm{msec}$ paired trials in session 1 of paired training. Arrowheads indicate the onset of the CS and the offset of the US.

of difference between trial types in the PND18 neurons. There also appears to be neuronal activity related to the movement of the eyelid during CR trials in PND25 neurons (McCormick et al., 1983), and the unconditioned startle-response to the tone in PND17-18 neurons (Mortimer, 1973; Stanton et al., 1992).

Within-group comparisons between sessions 1 and 5 among PND17-18 units revealed a significantly later onset latency during the $6 \mathrm{msec}$ paired trials in session $5(t=3.576, p<0.01)$. Withingroup comparisons between sessions 1 and 5 among PND24-25 units reveal a significantly later onset $(t=6.938, p<0.01)$ and peak $(t=3.397, p<0.01)$ during 6 msec paired trials; significantly later onset $(t=3.21, p<0.01)$ and peak $(t=3.686, p<0.01)$ latencies during $1 \mathrm{msec}$ paired trials; and a significantly later onset $(t=$ $3.069, p<0.01$ ) latency during $6 \mathrm{msec}$ US-alone trials during session 5 (Table 1).

The high responsivity to the US in inferior olive neurons in PND17-18 and PND24-25 rat pups throughout training is consistent with previous studies (Armstrong et al., 1968; Armstrong, 1974; Gellman et al., 1983, 1985; Sears and Steinmetz, 1991; Weiss et al., 1993). Moreover, the relatively low spontaneous rate $(<1$ $\mathrm{Hz}$ ) of firing during the brief prestimulus baseline period $(595 \mathrm{msec}$ in pretraining and $300 \mathrm{msec}$ for paired CS-US trials) is consistent with other studies of DAO or complex spike activity during eyeblink conditioning (Berthier and Moore, 1986; Sears and Steinmetz, 1991; Kim et al., 1998). There are three possible reasons for relatively low baseline firing during conditioning trials. First, to minimize the amount of "noise" in the behavioral and neuronal data, we waited until the rats were completely still before a trial was initiated. Therefore, the data are from selectively chosen conditioning trials when the animals' EMG records were showing the least amount of activity. Second, the animals develop a conditioned fear of the tone CS used in training, indicated in both groups by conditioned suppression of a drinking response during tone presentations in the training environment (Freeman et al., 1995a). The cerebellum may be contributing to the postural tone of a "freezing" animal (Terzuolo and Terzian, 1953; Llinas, 1964; Manni et al., 1964) and perhaps also providing a weak inhibition of inferior olive activity through the GABAergic nucleo-olivary pathway (Nelson et al., 1989; De Zeeuw et al., 1990; Fredette and Mugnaini, 1991), lowering the spontaneous firing rate compared with a decerebrate, anesthetized, or resting animal from which most spontaneous measures have been taken (Armstrong, 1974). Finally, the brief prestimulus baseline (300 msec in paired trials) may provide a poor sampling window for estimating spontaneous activity in lowfrequency neurons. However, the range of spontaneous DAO activity in the present study was $0.2-3 \mathrm{~Hz}$, which is consistent with previous studies (Armstrong et al., 1968; Armstrong, 1974; Crill,
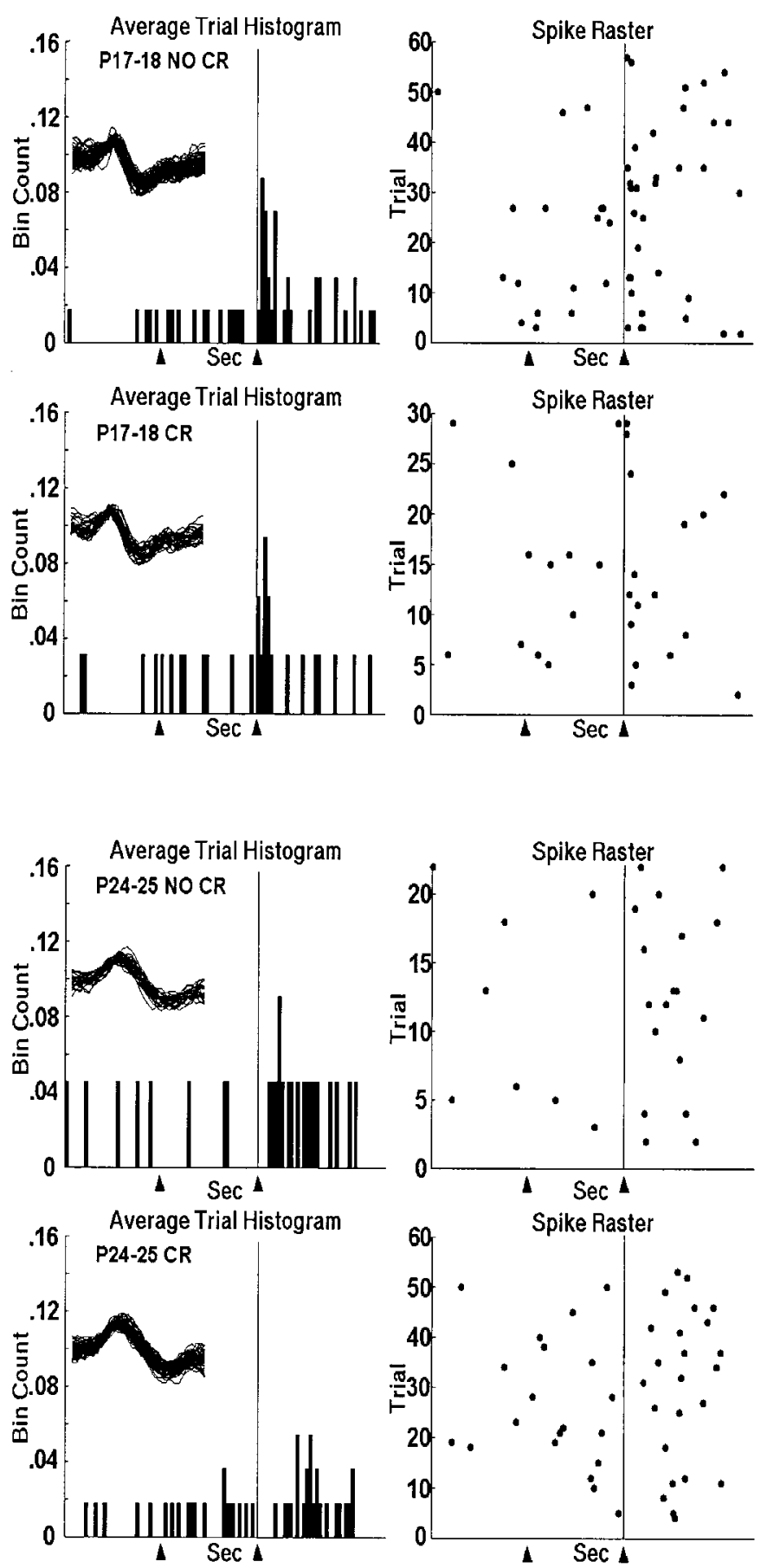

Figure 7. Top two panels, Histogram and raster plots of a representative unit recorded in the DAO during session 5 of paired training from an infant rat trained on PND18 during trials in which no eye-blink CR was performed (top) and during trials in which an eye-blink CR was performed (bottom). Bottom two panels, Histogram and raster plot of a representative unit recorded in the DAO during session 5 of paired training from an infant rat trained on PND25 during trials in which no eye-blink CR was performed (top) and during trials in which an eye-blink CR was performed (bottom). The arrowheads and vertical line at $0.6 \mathrm{sec}$ indicate the points in the trial when CS onset and US offset occurred. The spike overlays are $1.6 \mathrm{msec}$.

1970; Cook and Wiesendanger, 1976; Gellman et al., 1983, 1985; Sears and Steinmetz, 1991; Weiss et al., 1993).

It is possible that the synchronous neuronal ensemble response to the US among DAO neurons at each age in the present study is attributable to the spread of excitation via electrotonic coupling in the inferior olive (Llinas et al., 1974; Sotelo et al., 1974; Llinas and 
A.

PND17-18

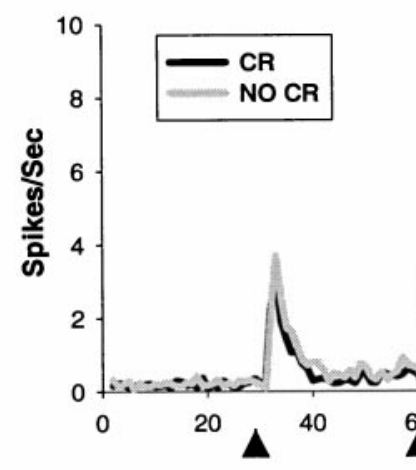

B.

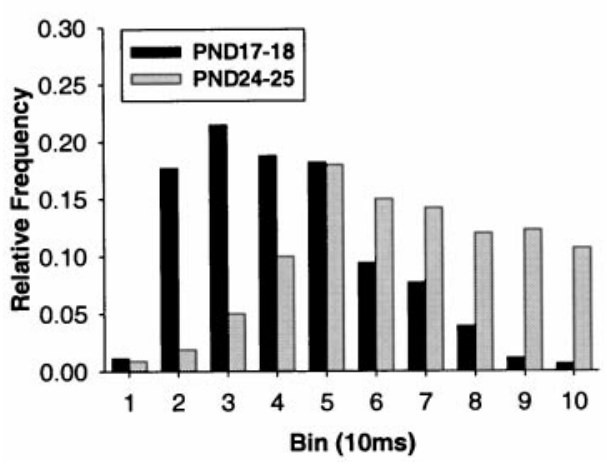

PND24-25

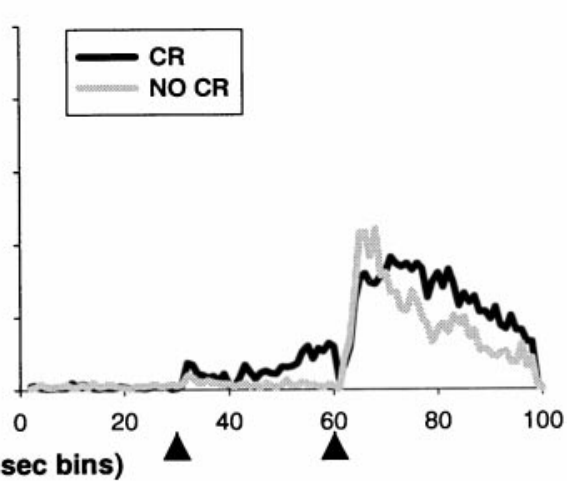

Figure 8. A, Mean neuronal activity during the entire trial length $(1 \mathrm{sec})$ for all of the single units recorded from the DAO on PND17-18 $(l e f t)$ and PND24-25 (right) in session 5 of paired training. In each plot, the gray line is a plot of DAO mean activity during trials in which an eye-blink CR was not performed, and the black line is a plot of DAO mean activity during trials in which an eye-blink CR was performed. Arrowheads indicate the onset of the CS and the offset of the US. $B$, The distribution of peak latencies of responses to the US in DAO neurons from PND18 (black bars) and PND25 (gray bars) rat pups during paired trials in session 5.

Sasaki, 1989; Lang et al., 1999). Electrotonic coupling provides a means of communication among olive neurons without the necessity of action potentials and could therefore contribute to the time-locked relationship to the US that most neurons exhibited.

\section{Inferior olive stimulation}

Eyelid responses were elicited in rats from both age groups by stimulation of the inferior olive. After training, a $50 \mu \mathrm{sec}$ squarepulse was delivered through the recording electrodes to assess the possibility that direct olivary stimulation could lead to muscle activity. The current started at $5 \mu \mathrm{A}$ and was raised in steps of 10 $\mu \mathrm{A}$ until eyelid EMG activity or movement was detected (see Materials and Methods). Current levels ranging from 200 to 850 $\mu \mathrm{A}$ elicited eyelid EMG activity. No age-related differences in response-eliciting current level were detected. As the current intensity was increased, the amplitude of the eyelid response increased, and additional responses were elicited. Responses elicited by inferior olive stimulation other than eyelid movement included movement of the facial musculature, nose, and eye (Boylls, 1978; Gellman et al., 1985; Mauk et al., 1986; Steinmetz et al., 1989). At higher current levels $(>900 \mu \mathrm{A})$, electrode placements that were too dorsal (e.g., ventral gigantocellular reticular nucleus) or too ventral (e.g., principal and medial accessory olive) elicited nonspecific head jerks or nothing at all.

\section{DISCUSSION}

Developmental changes were observed in eye-blink conditioning and neuronal activity in the rostromedial region of the DAO. There was an age-related increase in the rate and magnitude of eye-blink conditioning, which replicated the results of previous studies (Stanton et al., 1992; Freeman et al., 1993, 1995a,b; Freeman and Nicholson, 2000). Several significant differences in neuronal activity in the DAO were observed. First, the magnitude of the DAO activity elicited by the US decreased with age. This developmental trend was first evident in pretraining and remained throughout training (Figs. 4B, 6, 8A). Second, the latency of the peak response to the US increased with age in paired and US-alone trials. This developmental trend was also first evident in pretraining and remained throughout training (Table 1). Third, the agerelated differences in the magnitude and timing of the neuronal response appear to be the result of a more consistent and highly synchronized response to the US in PND17-18 rat pups. Fourth, the synchrony of activity among DAO neurons in PND17-18 rats was not modified during CR trials, whereas the activity of DAO neurons in PND24-25 rats appeared to be desynchronized or delayed during CR trials. The developmental trends in US-elicited neuronal activity indicate that neurons in the DAO produce a stronger and more synchronized response in younger rats.

The developmental changes in DAO activity may appear to be inconsistent with our previous proposal that the ontogeny of eyeblink conditioning depends on developmental changes in the induction of plasticity caused by maturation of the US input to the cerebellar deep nuclei (Freeman and Nicholson, 2000). However, the developmental changes in neuronal activity in the inferior olive may reflect dynamic interactions between multiple developmental processes within the eye-blink circuitry. The idea that acquisition and maintenance of conditioned responses in infants depend on dynamic interactions between components of the eye-blink conditioning circuitry is consistent with current models of the neural mechanisms of eye-blink conditioning in adult organisms (Bartha et al., 1991; Bullock et al., 1994; Gluck et al., 1995; Raymond et al., 1996; Mauk and Donegan, 1997; Moore and Choi, 1997).

One of the most likely sites for dynamic interactions between developmental processes within the learning circuitry is the projection from the cerebellar deep nuclei to the inferior olive. A reasonable mechanism for the developmental decrease in the neuronal response to the US in the DAO is that the GABAergic nucleo-olivary connection becomes more effective from PND17 to 


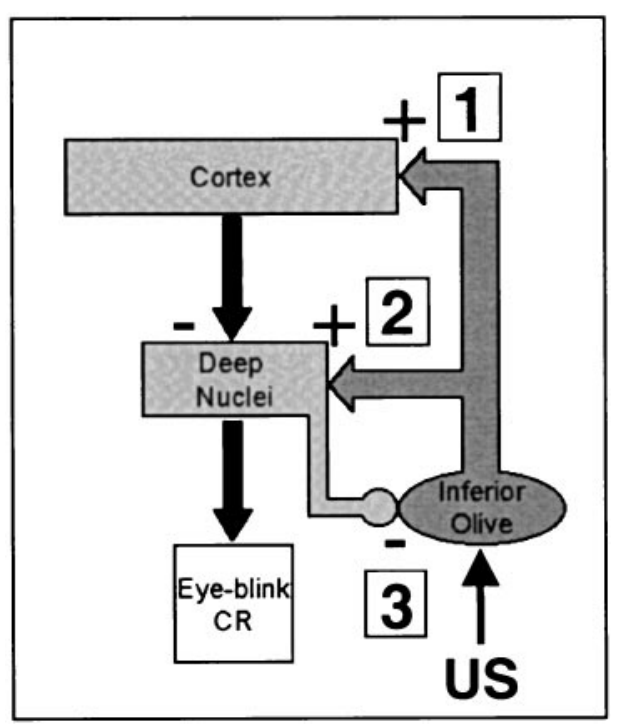

Figure 9. Simplified diagram of possible sites of developmental changes within the olivo-cerebellar circuit (see Discussion for details).

PND24 (Nelson et al., 1989; De Zeeuw et al., 1990; Fredette and Mugnaini, 1991) (Fig. 9, 3).

A recent experiment by Lang et al. (1996) may provide insight into how developmental changes in the nucleo-olivary pathway could contribute to the developmental differences in eye-blink conditioning. By applying the GABA antagonist picrotoxin to the inferior olive in adult animals, Lang et al. (1996) were able to increase synchrony among complex spikes in the cerebellar cortex. The same increase in synchrony occurred with muscimol inactivation or chemical lesions of the cerebellar deep nuclei, directly implicating the role of nucleo-olivary feedback in complex spike synchrony. Lang et al. (1996) proposed that application of picrotoxin to the inferior olive prevented the deep nuclei from decoupling olive cells, which then spread excitation to other nearby olive cells through electrotonic synapses within the olive (Llinas, 1974; Llinas et al., 1974; Fredette and Mugnaini, 1991). If there is a developmental difference in the nucleo-olivary pathway, then the functional decoupling of olive cells will occur less in the younger rats, and the electrotonic spread of excitation among DAO cells will be greater in PND17-18 rats, which will have the effect of increasing magnitude and synchrony of the responses among DAO neurons. This is exactly what was found in the DAO activity in the PND17-18 rats in the present experiment.

The modifiability of neuronal firing within the inferior olive during trials with eyelid CRs in PND24-25 rat pups is generally consistent with past studies (Gilbert and Thach, 1977; Gellman et al., 1983; McCormick et al., 1983; Berthier and Moore, 1986; Andersson and Armstrong, 1987; Sears and Steinmetz, 1991; Hesslow and Ivarsson, 1996; Horn et al., 1996; Kim et al., 1998; Apps and Lee, 1999) and provides additional support for the idea that there are developmental changes in the nucleo-olivary projections. The lack of CR-related inhibition of the US-elicited response in PND17-18 neurons is consistent with the lower level of CR-related neuronal activity in the cerebellar interpositus nucleus at this age (Freeman and Nicholson, 2000). It is possible that the broadened ensemble neuronal response during CR trials (Fig. 8A) in PND24-25 neurons is related to the functional decoupling of olive neurons by the nucleo-olivary projection (Gellman et al., 1985; Sears and Steinmetz, 1991; Horn et al., 1996, 1998), which may have the effect of inhibiting or significantly delaying an olivary response to the US. The presence of desynchronization rather than nearly total inhibition of the DAO response on CR trials (Sears and Steinmetz, 1991) in PND24-25 rat pups may be attributable to the nature of the US used in the present study (periorbital shock). Gellman et al. (1985) report that shock elicits a less variable and shorter latency response in the inferior olive than air puffs or taps. The differences in stimulus-elicited responses in the DAO provide a potential explanation for the discrepancy between the present data and the data of Sears and Steinmetz (1991), who used an air puff US and found almost complete inhibition of DAO activity during CRs. Alternatively, the relatively weaker CR-related modification of DAO activity in PND24-25 rats may be attributable to immaturity of the nucleo-olivary pathway at this age.

The modest CR-related activity in the DAO in P24-25 rats may be attributable to either response production (Llinas and Welsh, 1993; Welsh et al., 1995) or proprioception during an ongoing movement (Apps and Lee, 1999). Gellman et al. (1985) reported that some olivary neurons are responsive to proprioceptive stimuli during movement. Gellman et al. (1985) also reported that $21 \%$ of olivary neurons show a weak but notable modulation of their response during movement, which is similar to our weak but notable activity during the CR in the PND24-25 rat pups. Apps and Lee (1999) found the excitability of some cerebellar cortical responses (using Purkinje cell complex spikes as an index of excitability) to be highest during the swing phase of a stepping movement, whereas other cells demonstrate a higher excitability during the stance phase of movement. They concluded that the regions of cerebellar cortex with different levels of excitability during different phases of movement may act to monitor climbing fiber inputs at different times during movement. The results reported in the present experiment are consistent with these and other reports of olivary or complex spike excitability during movement (Gilbert and Thach, 1977; Berthier and Moore, 1986; Welsh et al., 1995).

Why is there a developmental increase in learning when there is a developmental decrease in US-elicited activity in the DAO? The two most likely points within the olivo-cerebellar circuitry where developmental processes might limit induction of cerebellar plasticity, and therefore limit learning, are the olivo-nuclear and olivocortical synapses (Fig. 9, 1 and 2). Although the responses of DAO neurons to the US are greater in the younger rats, it may be that the olivo-nuclear synapses have not fully matured (Fig. 9, 2). Developmental changes in olivo-nuclear synaptic efficacy would produce a weaker US input to the cerebellar interpositus nucleus and limit the induction of cerebellar plasticity in younger rats. Indirect evidence for this potential developmental process comes from a previous study, which demonstrated that neurons in the interpositus nucleus of P17-18 rats exhibited a substantially lower magnitude response to the US than the interpositus neurons of P24-25 rats (Freeman and Nicholson, 2000). In addition, preliminary findings indicate that the amplitude of the excitatory field potential in the interpositus nucleus produced by stimulation of the inferior olive (Kitai et al., 1977; Delgado-Garcia and Gruart, 1995) increases dramatically between PND17 and PND24 (D. A. Nicholson and J. H. Freeman, unpublished observations). A developmental difference in synaptic efficacy of olivo-nuclear synapses would also have the indirect effect of reducing cerebellar inhibition of the DAO (as described above) (Fig. 9, 3).

Another contributing mechanism to the ontogeny of eye-blink conditioning may be found in developmental changes in the synaptic physiology of the olivo-cortical pathway. If the connections between the climbing fibers of the inferior olive and the cerebellar cortex (Fig. 9, 1) are more robust than the climbing fiber input to the interpositus nucleus (Fig. 9, 2) in PND17-18 rat pups, then the stronger inhibitory action of the Purkinje cells (Ito et al., 1970; Ito and Simson, 1971) would further limit postsynaptic excitation to climbing fiber input within the interpositus nucleus. Previous neurophysiological studies provide indirect evidence for this putative developmental mechanism. For instance, the duration of the postsynaptic response in Purkinje cells after stimulation of climbing fibers shows a developmental decrease from PND5 to PND21 (Crepel, 1971, 1972, 1974; Puro and Woodward, 1977a,b), and there is a developmental decrease in the number of spikes in each complex spike (Crepel, 1971, 1974). The stronger Purkinje cell activation by climbing fibers in younger animals could limit the induction of learning-related plasticity in the interpositus nucleus 
and also have the indirect effect of reducing nucleo-olivary inhibitory feedback, as described above (Fig. 9, 3).

The ontogeny of eye-blink conditioning undoubtedly depends on the dynamic interactions of developmental processes within the olivo-cerebellar circuitry. In particular, the integrated effects of developmental changes in the efficacy of olivo-nuclear, nucleoolivary, and olivo-cortical projections may account for the ontogenetic emergence of eye-blink conditioning.

\section{REFERENCES}

Altman J (1972) Postnatal development of the cerebellar cortex in the rat. II. Phases in the maturation of Purkinje cells and of the molecular layer. J Comp Neurol 145:399-463.

Altman J (1982) Morphological development of the rat cerebellum and some of its mechanisms. In: The cerebellum: new vistas (Palay SL, Chan-Palay V, eds), pp 8-49. Berlin: Springer.

Andersson G, Armstrong DM (1987) Complex spikes in Purkinje cells in the lateral vermis (b zone) of the cat cerebellum during locomotion. J Physiol (Lond) 385:107-134.

Apps R, Lee S (1999) Gating of transmission in climbing fibre paths to cerebellar cortical $\mathrm{C} 1$ and $\mathrm{C} 3$ zones in the rostral paramedian lobule during locomotion in the cat. J Physiol (Lond) 516:875-883.

Armstrong DM (1974) Functional significance of connections of the inferior olive. Physiol Rev 54:358-417.

Armstrong DM, Harvey RJ (1968) Responses of a spino-olivo-cerebellar pathway in the cat. J Physiol (Lond) 194:147-168.

Armstrong DM, Eccles JC, Harvey RJ, Matthews PB (1968) Responses in the dorsal accessory olive of the cat to stimulation of hind limb afferents. J Physiol (Lond) 194:125-145.

Barmack NH, Hess DT (1980) Multiple-unit activity evoked in dorsal cap of inferior olive of the rabbit by visual stimulation. J Neurophysiol 43:151-164.

Bartha GT, Thompson RF, Gluck MA (1991) Sensorimotor learning and the cerebellum. In: Visual structures and integrated functions (Arbib ME, Ewert J, eds), pp 381-396. Berlin: Springer.

Berry M, Bradley P (1976) The growth of dendritic trees of Purkinje cells in the cerebellum of the rat. Brain Res 112:1-35.

Berthier NE, Moore JW (1986) Cerebellar Purkinje cell activity related to the classically conditioned nictitating membrane response. Exp Brain Res 63:341-350.

Boylls CC (1978) Prolonged alterations of muscle activity induced in locomoting premammillary cats by microstimulation of the inferior olive. Brain Res 159:445-450.

Bullock D, Fiala JC, Grossberg S (1994) A neural model of timed response learning in the cerebellum. Neural Networks 7:1101-1114.

Carew TJ (1989) Developmental assembly of learning in Aplysia. Trends Neurosci 12:389-394.

Cook JR, Wiesendanger M (1976) Input from trigeminal cutaneous afferents to neurones of the inferior olive in rats. Exp Brain Res 26:193-202.

Crepel F (1971) Maturation of climbing fiber responses in the rat. Brain Res 35:272-276.

Crepel F (1972) Maturation of cerebellar Purkinje cells. I. Postnatal evolution of the Purkinje cell spontaneous firing in the rat. Exp Brain Res 14:463-479.

Crepel F (1974) Excitatory and inhibitory processes acting upon cerebellar Purkinje cells during maturation in the rat; influence of hypothyroidism. Exp Brain Res 20:403-420.

Crill WE (1970) Unitary multiple-spiked responses in cat inferior olive nucleus. J Neurophysiol 33:199-209.

Delgado-Garcia JM, Gruart A (1995) Signalling properties of deep cerebellar nuclei neurones. In: Neural control of movement (Ferrel WR, Proske U, eds), pp 225-232. New York: Plenum.

Diamond A (1990) The development and neural bases of memory functions as indexed by the AB and delayed response tasks in human infants and infant monkeys. In: The development and neural bases of higher cognitive functions, Vol 8 (Diamond A, ed), pp 267-317. New York: Annals of the New York Academy of Sciences.

Du W, Harvey JA (1997) Harmaline-induced tremor and impairment of learning are both blocked by dizocilpine in the rabbit. Brain Res 745:183-188

De Zeeuw CI, Ruigrok TJ, Holstege JC, Jansen HG, Voogd J (1990) Intracellular labeling of neurons in the medial accessory olive of the cat: II. Ultrastructure of dendritic spines and their GABAergic innervation. J Comp Neurol 300:478-494.

Freeman Jr JH, Nicholson DA (1999) Neuronal activity in the cerebellar interpositus and lateral pontine nuclei during inhibitory classical conditioning of the eyeblink response. Brain Res 833:225-233.

Freeman Jr JH, Nicholson DA (2000) Developmental changes in eye-blink conditioning and neuronal activity in the cerebellar interpositus nucleus. J Neurosci 20:813-819.

Freeman Jr JH, Stanton ME (1991) Fimbria-fornix transections disrupt the ontogeny of delayed alternation but not position discrimination in the rat. Behav Neurosci 105:386-395.

Freeman Jr JH, Spencer CO, Skelton RW, Stanton ME (1993) Ontogeny of eyeblink conditioning in the rat: effects of US intensity and interstimulus interval on delay conditioning. Psychobiology 21:233-242.

Freeman Jr JH, Barone Jr S, Stanton ME (1995a) Disruption of cerebellar maturation by an antimitotic agent impairs the ontogeny of eyeblink conditioning in rats. J Neurosci 15:7301-7314.

Freeman Jr JH, Carter CS, Stanton ME (1995b) Early cerebellar lesions impair eyeblink conditioning in developing rats: differential effects of unilateral lesions on postnatal day 10 or 20. Behav Neurosci 109:893-902.

Fredette BJ, Mugnaini E (1991) The GABAergic cerebello-olivary projection in the rat. Anat Embryol (Berl) 184:225-243.

Gardette R, Debono M, Dupont JL, Crepel F (1985) Electrophysiological studies on the postnatal development of intracerebellar nuclei neurons in rat cerebellar slices maintained in vitro. I. Postsynaptic potentials. Dev Brain Res 19:47-55.

Gellman R, Houk JC, Gibson AR (1983) Somatosensory properties of the inferior olive of the cat. J Comp Neurol 215:228-243.

Gellman R, Gibson AR, Houk JC (1985) Inferior olivary neurons in the awake cat: detection of contact and passive body displacement. J Neurophysiol 54:40-60.

Gilbert PF, Thach WT (1977) Purkinje cell activity during motor learning. Brain Res 128:309-328.

Gluck MA, Myers CE, Thompson RF (1995) A computational model of the cerebellum and motor-reflex conditioning. In: An introduction to neural and electronic networks (Zornetzer SE, Davis JL, Lau C, McKenna T, eds), pp 91-98. San Diego: Academic.

Gormezano I (1966) Classical conditioning. In: Experimental methods and instrumentation in psychology (Sidowski JB, ed), pp 385-420. New York: McGraw-Hill.

Gormezano I, Schneiderman N, Deaux EG, Fuentes I (1962) Nictitating membrane: classical conditioning and extinction in the albino rabbit. Science 138:33-34.

Gormezano I, Kehoe EJ, Marshall BS (1983) Twenty years of classical conditioning research with the rabbit. Prog Psychobiol Physiol Psychol 10:197-275.

Green RJ, Stanton ME (1989) Differential ontogeny of working memory and reference memory in the rat. Behav Neurosci 103:98-105.

Harvey JA, Romano AG (1993) Harmaline-induced impairment of Pavlovian conditioning in the rabbit. J Neurosci 13:1616-1623.

Headley PM, Lodge D (1976) Studies on field potentials and on single cells in the inferior olivary complex of the rat. Brain Res 101:445-459.

Hesslow G, Ivarsson M (1996) Inhibition of the inferior olive during conditioned responses in the decerebrate ferret. Exp Brain Res 110:36-46.

Horn KM, Van Kan PL, Gibson AR (1996) Reduction of rostral dorsal accessory olive responses during reaching. J Neurophysiol 76:4140-4151.

Horn KM, Hamm TM, Gibson AR (1998) Red nucleus stimulation inhibits within the inferior olive. J Neurophysiol 80:3127-3136.

Hunt PS, Campbell BA (1997) Developmental dissociation of components of conditioned fear. In: Learning, motivation, and cognition: the functional behaviorism of Robert C. Bolles (Bouton ME, Fanselow MS, eds), pp 53-74. Washington, DC: American Psychological Association.

Ito M (1984) The cerebellum and neural control. New York: Raven.

Ito M, Simson JI (1971) Discharges in Purkinje cell axons during climbing fiber activation. Brain Res 31:215-219.

Ito M, Yoshida M, Obata K, Kawai N, Udo M (1970) Inhibitory control of intracerebellar nuclei by the purkinje cell axons. Exp Brain Res 10:64-80.

Kim JJ, Krupa DJ, Thompson RF (1998) Inhibitory cerebello-olivary projections and blocking effect in classical conditioning. Science 279:570-573.

Kitai ST, McCrea RA, Preston RJ, Bishop GA (1977) Electrophysiological and horseradish peroxidase studies of precerebellar afferents to the nucleus interpositus anterior. I. Climbing fiber system. Brain Res 122:197-214.

Kubota Y, Wolske M, Poremba A, Kang E, Gabriel M (1996) Stimulusrelated and movement-related single-unit activity in rabbit cingulate cortex and limbic thalamus during performance of discriminative avoidance behavior. Brain Res 721:22-38.

Lang EJ, Sugihara I, Llinas R (1996) GABAergic modulation of complex spike activity by the cerebellar nucleoolivary pathway in rat. J Neurophysiol 76:255-275.

Lang EJ, Sugihara I, Welsh JP, Llinas R (1999) Patterns of spontaneous Purkinje cell complex spike activity in the awake rat. J Neurosci 19:2728-2739.

Lavond DG, Kim JJ, Thompson RF (1993) Mammalian brain substrates of aversive classical conditioning. Annu Rev Psychol 44:317-342.

Llinas R (1964) Mechanisms of supraspinal actions upon spinal cord activities. Differences between reticular and cerebellar inhibitory actions upon alpha extensor motoneurons. J Neurophysiol 27:1117-1126.

Llinas R (1974) Eighteenth Bowditch lecture. Motor aspects of cerebellar control. Physiologist 17:19-46.

Llinas R, Sasaki K (1989) The functional organization of the olivocerebellar system as examined by multiple Purkinje cell recordings. Eur J Neurosci 1:587-602.

Llinas R, Welsh JP (1993) On the cerebellum and motor learning. Curr Opin Neurobiol 3:958-965. 
Llinas R, Baker R, Sotelo C (1974) Electrotonic coupling between neurons in cat inferior olive. J Neurophysiol 37:560-571.

Manni E, Henatsch HD, Henatsch E-M, Dow RS (1964) Localization of facilitory and inhibitory sites in and around the cerebellar nuclei affecting limb posture, alpha and gamma motoneurons. J Neurophysiol 27:210-228.

Marcus EA, Carew TJ (1998) Developmental emergence of different forms of neuromodulation in Aplysia sensory neurons. Proc Natl Acad Sci USA 95:4726-4731.

Mauk MD, Donegan NH (1997) A model of Pavlovian eyelid conditioning based on the synaptic organization of the cerebellum. Learn Mem 3:130-158.

Mauk MD, Steinmetz JE, Thompson RF (1986) Classical conditioning using stimulation of the inferior olive as the unconditioned stimulus. Proc Natl Acad Sci USA 83:5349-5353.

McCormick DA, Lavond DG, Thompson RF (1983) Neuronal responses of the rabbit brainstem during performance of the classically conditioned nictitating membrane (NM)/eyelid response. Brain Res 271:73-88.

McCormick DA, Steinmetz JE, Thompson RF (1985) Lesions of the inferior olivary complex cause extinction of the classically conditioned eyeblink response. Brain Res 359:120-130.

Mintz M, Lavond DG, Zhang AA, Yun Y, Thompson RF (1994) Unilateral inferior olive NMDA lesion leads to unilateral deficit in acquisition and retention of eyelid classical conditioning. Behav Neural Biol 61:218-224.

Moore JW, Choi JS (1997) The TD model of classical conditioning: response topography and brain implementation. In: Neural network models of cognition: biobehavioral foundations. Advances in psychology (Donahoe JW, Dorsel VP eds), pp 387-405. Amsterdam: Elsevier Science.

Mortimer JA (1973) Temporal sequence of cerebellar Purkinje and nuclear activity in relation to the acoustic startle response. Brain Res 50:457-462

Nelson BJ, Adams JC, Barmack NH, Mugnaini E (1989) Comparative study of glutamate decarboxylase immunoreactive boutons in the mammalian inferior olive. J Comp Neurol 286:514-539.

Puro DG, Woodward DJ (1977a) Maturation of evoked climbing fiber input to rat cerebellar Purkinje cells I. Exp Brain Res 28:85-100.

Puro DG, Woodward DJ (1977b) Maturation of evoked mossy fiber input to rat cerebellar Purkinje cells II. Exp Brain Res 28:427-441.
Raymond JL, Lisberger SG, Mauk MD (1996) The cerebellum: a neuronal learning machine? Science 272:1126-1131.

Rudy JW (1992) Development of learning: from elemental to configural associative networks. In: Advances in infancy research (Rovee-Collier C, Lipsitt LP, eds), pp 247-289. Trenton, NJ: ABLEX.

Sears LL, Steinmetz JE (1991) Dorsal accessory inferior olive activity diminishes during acquisition of the rabbit classically conditioned eyelid response. Brain Res 545:114-122.

Sotelo C, Llinas R, Baker R (1974) Structural study of inferior olivary nucleus of the cat: morphological correlates of electrotonic coupling. J Neurophysiol 37:541-559.

Stanton ME (2000) Multiple memory systems, development and conditioning. Behav Brain Res 110:25-37.

Stanton ME, Freeman Jr JH (1999) Developmental studies of eyeblink conditioning in a rat model. In: Eyeblink classical conditioning: animal (Woodruff-Pak DS, Steinmetz JE, eds), pp 105-134. Amsterdam: Kluwer.

Stanton ME, Freeman Jr JH, Skelton RW (1992) Eyeblink conditioning in the developing rat. Behav Neurosci 106:657-665.

Steinmetz JE (1998) The localization of a simple type of learning and memory: the cerebellum and classical eyeblink conditioning. Curr Dir Psychol Sci 7:72-77.

Steinmetz JE, Lavond DG, Thompson RF (1989) Classical conditioning in rabbits using pontine nucleus stimulation as a conditioned stimulus and inferior olive stimulation as an unconditioned stimulus. Synapse 3:225-233.

Terzuolo CA, Terzian H (1953) Cerebellar increase of postural tonus after deafferentation and labyrinthectomy. J Neurophysiol 16:551-561.

Thach WT, Goodkin HP, Keating JG (1992) The cerebellum and the adaptive coordination of movement. Annu Rev Neurosci 15:403-442.

Thompson RF, Krupa DJ (1994) Organization of memory traces in the mammalian brain. Annu Rev Neurosci 17:519-549.

Weiss C, Disterhoft JF, Gibson AR, Houk JC (1993) Receptive fields of single cells from the face zone of the cat rostral dorsal accessory olive. Brain Res 605:207-213.

Welsh JP, Lang EJ, Sugihara I, Llinas R (1995) Dynamic organization of motor control within the olivocerebellar system. Nature 374:453-457.

Yeo CH, Hardiman MJ, Glickstein M (1986) Classical conditioning of the nictitating membrane response of the rabbit. IV. Lesions of the inferior olive. Exp Brain Res 63:81-92. 